The work described in this thesis was carried out by tue under the supperwision of Prof. (Mrs), S.M.I).N. Wickramasinghe and Proff. (IWis $\$$ )MMLI.Thiadbrewand at report on this has not been submitted to any other University for another degree.

Dr. (Miss). S. S. IIddamaideníya
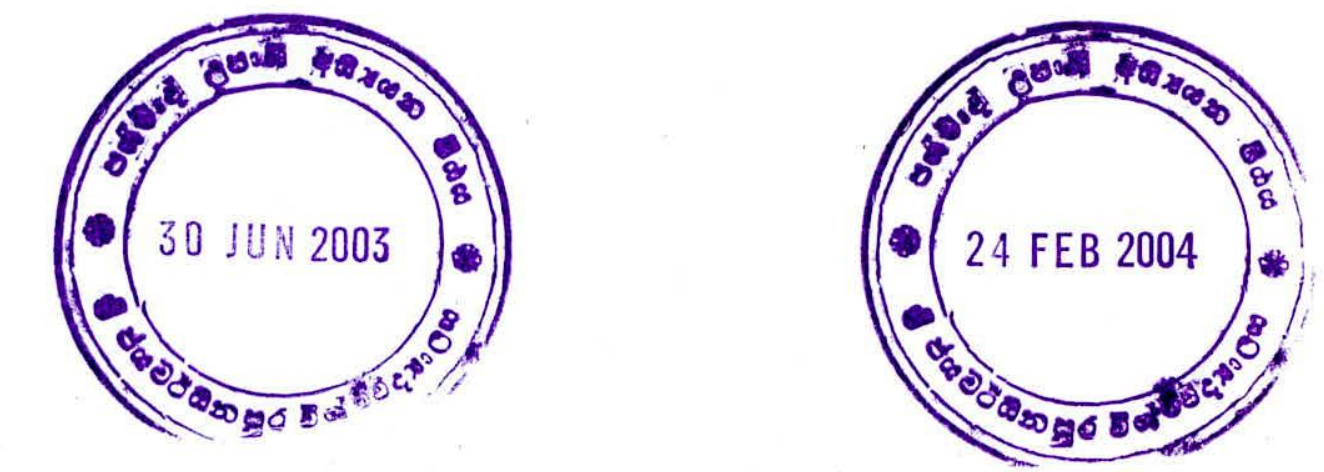
We certify that the above statement made by the candidate is true and that this thesis is suitable for submission to the University for the purpose of evaluation.

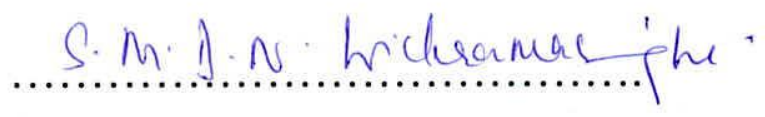

Supervisor,

Prof. (Mrs) S.M.D.N. Wickramasighe,

Department of Biochemistry,

Faculty of Medical Sciences,

University of Sri Jayawardenepura,

Gangodawila,

Nugegoda.

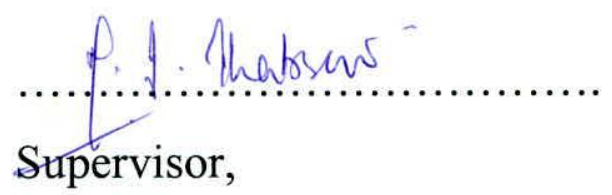

Prof. (Mrs) M.I. Thabrew,

Department of Biochemistry and

Clinical Chemistry,

Faculty of Medicine

University of Kelaniya,

Ragama. 


\section{Investigation of the effects of a traditional Sri Lankan}

\section{Medicine on Hepatocarcinogenesis}

by

Samantha Sudharshani Iddamaldeniya

Thesis submitted to the University of Sri Jayawardenepura for the award of the degree of Master of Philosophy in Biochemistry on 30 $0^{\text {th }}$ June 2003 


\section{Contents}

Table of Contents i

List of Tables $\quad$ ix

List of Figures $\quad$ xi

List of Plates $\quad$ xiii

ACKNOWLEDGEMENTS Xv

ABSTRACT xviii

\section{INTRODUCTION}

$\begin{array}{ll}\text { 1.1 Background and justification } & 1\end{array}$

1.2 Scope of the study 5

1.2.1 General Objective $\quad 5$

1.2.2 Specific objectives 5

\section{LITERATURE REVIEW}

2.1 Concept of cancer in allopathic medicine $\quad 6$

$\begin{array}{ll}\text { 2.1.1 Historical aspects } & 6\end{array}$

$\begin{array}{ll}\text { 2.1.2 Neoplasia } & 7\end{array}$

$\begin{array}{ll}\text { 2.1.3 Tumour nomenclature } & 7\end{array}$

2.1.4 Grading and staging of neoplasia 9

$\begin{array}{ll}\text { 2.2 Pathogenesis of neoplasia } & 10\end{array}$

2.2.1 Control of cell growth 11 
$\begin{array}{ll}2.3 \text { Biology of tumour growth } & 14\end{array}$

2.3.1 Malignant change in the target cell- transformation $\quad 14$

$\begin{array}{ll}\text { 2.3.1.1 Chemical carcinogens } & 15\end{array}$

$\begin{array}{lr}\text { 2.3.1.1.i Nitrosamines and Nitrosamides } & 17\end{array}$ (N-Nitroso Compounds)

2.3.1.1.ii Metabolic pathways leading to carcinogen activation and detoxication.

2.4 Chemical carcinogenesis

2.4.1 Mechanisms involved in initiation and promotion of chemical carcinogenesis

2.4.1.1 Initiation of carcinogenesi

$\begin{array}{ll}\text { 2.4.1.1.i Metabolic activation of carcinogens } & 23\end{array}$

2.4.1.1.ii Molecular targets of initiation 24

2.4.1.1.iii Initiated Cell 25

2.4.1.2 Promotion of carcinogenesis 26

$\begin{array}{ll}2.5 \text { Physical carcinogens } & 27\end{array}$

$\begin{array}{ll}\text { 2.6 Viral carcinogens } & 27\end{array}$

2.7 Growth of transformed cell 28

2.7.1 Clonality of tumours 28

2.7.2 Kinetics of tumour cell growth 29

2.8 Predisposing factors for carcinogenesis 30

2.9 Cancer suppressor genes $\quad 31$ 
2.10.1 Definition 32

2.10.2 Features of a tumour marker 34

2.10.3 Glutathione S-transferase 35

2.10.3.1 Introduction 35

2.10.3.2 Classification 35

$\begin{array}{ll}\text { 2.10.3.3 Structure } & 36\end{array}$

$\begin{array}{ll}\text { 2.10.3.4 Functions } & 37\end{array}$

2.10.3.4.i As a tumour marker 37

2.10.3.4.i.i Mechanism of action of inducing 38

GST-P foci

2.10.3.4.ii Detoxification properties 39

2.10.3.4.iii Other functions 39

2.11 Concept of cancer in Ayurveda $\quad 40$

2.11.1 Treatment of cancer in Ayurveda 42

2.11.1.1 Systemic 42

$\begin{array}{ll}\text { 2.11.1.2 Local } & 44\end{array}$

2.11.2 Plants used in Ayurveda for cancer 44

2.11.3 Plants with experimentally confirmed anti-cancer activity $\quad 45$

2.11.3.1 Anti cancer activity of plants in crude extract 45

2.11.3.2 Anti cancer activity of active principle/s $\quad 53$ isolated from plants

2.11.4 Formulations used for cancer treatment 57

2.11.5 Identified modes of actions of plant based anticarcinogens 58 
2.12 Botanical Features, major chemical constituents and medjcinal uses of Nigella sativa, Hemidesmus indicus and Smilax glabra.

2.12.1 Nigella sativa Linn.sp

2.12.1.1 Botanical features

2.12.1.2 Composition and major chemical constituents

2.12.1.3 Uses

2.12.2 Hemidesmus indicus (L) R.Br.

62

2.12.2.1 Botanical features

62

2.12.2.2 Composition and major chemical constituents 64

2.12.2.3 Uses 64

2.12.3 Smilax glabra Rox b. 65

2.12.3.1 Botanical features 65

2.12.3.2 Chemical composition major chemical constituents 66

2.12.3.3 Uses 66

2.12.4 Allium sativum (Garlic) 67

\section{MATERIALS AND METHODS}

\subsection{MATERIALS}

3.1.1 Experimental animals

$\begin{array}{ll}\text { 3.1.2 Plant materials } & 71\end{array}$

$\begin{array}{ll}\text { 3.1.3 Chemicals } & 71\end{array}$ 


\subsection{METHODS}

$\begin{array}{ll}\text { 3.2.1 Preparation of the plant decoction } & 73\end{array}$

3.2.2 Effects of the decoction on initiation and 74

promotion of carcinogenesis

3.2.2.1 Liver Medium Term Bioassay Protocol 74

for induction of Carcinogenesis

$\begin{array}{ll}\text { 3.2.2.2 Experimental Design } & 74\end{array}$

3.2.2.3 Dosage and administration of decoction and garlic 77

$\begin{array}{ll}\text { 3.2.2.4 Pentobarbital Anaesthesia } & 77\end{array}$

3.2.2.5 Partial Hepatectomy 78

$\begin{array}{ll}\text { 3.2.2.5.i Procedure } & 78\end{array}$

3.2.2.6 Collection and fixation of liver tissues $\quad 81$

3.2.2.7 10\% buffered formalin $\quad 81$

3.2.2.8 Processing, embedding, and cutting of liver tissues 81

3.2.2.9 Preparation of Poly-L Lysine coated slides 82

3.2.2.10 Glutathione S-transferase -P (GST-P, EC 2.5.1.18) Immunohistochemistry 82

3.2.2.10.i $\mathrm{H}_{2} \mathrm{O}_{2}$ for blocking endogenous peroxidase activity 82

3.2.2.10.ii $0.5 \mathrm{M}$ Tris / $\mathrm{HCl}$ buffer $\quad 83$

3.2.2.10.iii Phosphate buffered saline $\quad 83$

3.2.10.iv Diaminobenzidine Tetrahydrochloride solution and 83 development solution 
3.2.210.vi Immunohistochemistry Procedure for GST-P 84

3.2.211 Haematoxylin and Eosin (H \& E) staining 86

3.2.2.11.i Preparation of Harris's haematoxylin 86

$\begin{array}{ll}\text { 3.2.2.11.ii Preparation of Eosin } & 87\end{array}$

3.2.2.11.iii Preparation of acid alcohol 87

3.2.2.11.iv H \& E staining procedure $\quad 88$

3.2.3 Effects of decoction on tumour development 88

$\begin{array}{lr}\text { 3.2.3.1 Experimental design } & 88\end{array}$

3.2.3.2 Silver impregnation for reticulin fibers 90

3.2.3.2.i Preparation of Ammonical Silver nitrate solution 90

3.2.3.2.ii Preapration of $1 \%$ Potassium permangenate solution $\quad 90$

$\begin{array}{ll}\text { 3.2.3.2.iii Staining method for Reticulin fibers } & 90\end{array}$

3.3 Toxicity study $\quad 91$

3.3.1 Determination of $\mathrm{LD}_{50}$

3.3.2 Effects on haematological parameters 92

3.3.2.1 Determination of red blood cell count 93

3.3.2.2 Determination of white blood cell count 94

3.3.2.3 Determination of differential count 95

3.3.2.4 Determination of packed cell volume 96

3.3.2.5 Determination of haemoglobin concentration 97

3.3.2.6 Calculation of erythrocyte indices 100

$\begin{array}{ll}\text { 3.3.3 Effects on serum enzyme levels } & 100\end{array}$

3.3.4 Assessment of histological changes 103 
3.3.5 Effects on body weight gain, feed consumption ratio and body weight : liver weight ratio

3.3.6 Effects on reproductive ability

3.3.6.1 Preparation of vaginal smears

3.3.6.2 Effects on ovulatory activity

3.3.6.3 Effects on implantation

3.3.6.4 Effects on spermatocytogenicity

3.4 Studies to determine mechanism of action 106

3.4.1 Immunological studie

3.4.2 Antioxidant studies

3.4.2.1 Assay for free radical scavenging activity

3.4.2.2 Superoxide dismutase (SOD, 1.15.1.1) assay

3.4.2.3 Glutathione peroxidase assay (GPX, 1.11.1.9)

\section{RESULTS}

4.1 Effects of the decoction on initiation and promotion of hepatocarcinogenesis.

4.2 Effects of treatment with decoction for 34 weeks on

DEN- mediated tumour development in rat livers.

4.2.1 Post mortem findings

4.2.2 Haematoxylin and Eosin staining ( $\mathrm{H}$ and $\mathrm{E})$

4.2.3 Silver impregnation for reticulin fibers 
$\begin{array}{ll}\text { 4.3.1 } \mathrm{LD}_{50} \text { determination } & 124\end{array}$

4.3.2 Effects on haematological parameters 124

$\begin{array}{ll}\text { 4.3.4 Serum enzyme levels } & 124\end{array}$

4.3.5 Effects of the decoction on feed consumption, body weight gain $\quad 125$ and body weight : liver weight ratio

4.3.6 Histopathology

4.3.7 Effects on reproductive ability

4.3.7.1 Anti - ovulatory activity

4.3.7.2 Effects on implantation

4.3.7.3 Anti-spermatocytogenic activity

4.4 Studies to investigate possible mechanism of action of the decoction in tumour inhibition

4.4.1 Immunological studies

4.4.2 Antioxidant effects and GPX (glutathione peroxidase) activity 


\section{LIST OF TABLES}

Table 1.1 Cancer mortality worldwide $\quad 1$

Table 2.1 Differences between benign and malignant tumours 8

Table 2.2: Some known Growth Factors 13

Table 2.3: Some important viral carcinogens 28

Table 2.4: Tumour markers 33

Table 2.5: Diseases considered as maliganant in Ayurveda 41

Table 2.6: Plants used in Ayurveda for Cancer 44

Table 2.7: Plants with confirmed anti cancer activity 46 in the crude extract - by in vitro studies

Table 2.8: Plants with confirmed anti cancer activity 48 in the crude extract- in vivo studies.

Table 2.9: Plants with anti cancer activity

(active components isolated)-in vitro studies

Table 2.10: Plants with anti cancer activity (active components isolated)-in vivo studies.

Table 2.11: Formulations used for cancer treatment 57

Table 3.1: Feed formulae for rat and mouse 72

Table 3.2: Serial dilution of the decoction for DPPH assay 109

Table 4.1: Number of DEN -induced GST-P positive foci 115 in livers of rats treated with the decoction or garlic for ten weeks.

Table 4.2: Area of DEN -induced GST-P positive foci in livers of rats 116 treated with the decoction or garlic for ten weeks. 
Table 4.3: Number of DEN -induced GST-P positive cells in liver of rats treated with the decoction or garlic for ten weeks.

Table 4.4: A comparison of haematological parameters of rats control group with rats treated with the decoction for one month.

Table 4.5: Effects of decoction on serum enzyme levels after three months of treatment.

Table 4.6: Effects of the decoction on average feed consumption average body weight gain and body weight: liver weight ratio.

Table 4.7: Effects of the decoction on oestrus cycle

Table 4.8: Effects of decoction on implantation

Table 4.9: Effects of decoction on spermatocytogenic activity

Table 4.10: Effects of decoction on groups 1 (control) and 2 (test) lymphocyte markers 


\section{LIST OF FIGURES}

Figure.2.1: Flow chart depicting a simplified scheme of cancer

pathogenesis

Figure 2.2: Direct and indirect carcinogens

Figure 2.3: Actions of initiators and Promotors

Figure 2.4: The general scheme of events in chemical carcinogenesis

Figure 3.1: Assay method of short term study

Figure 3.2 a: Midline ventral incision

Figure 3.2 b: Mobilization of median and left lateral lobes

Figure 3.2 c: Severing two suspensory ligaments

Figure 3.2 d: Ligating the two liver lobes

Figure 3.2 e: Making several cuts on the liver

Figure 3.3: Assay method for long term study

Figure 3.4: Hb standard curve

Figure 4.1: Staining intensity of DEN-initiated liver GST-P positive foci in Wistar rats treated with decoction or garlic for ten weeks.

Figure 4.2: Effects of decoction treatment for nine months on number of GST-P positive cells of DEN-induced liver foci in Wistar rats.

Figure 4.3: Effects of decoction treatment for nine months on number of DEN induced GST-P positive foci in Wistar rats .

Figure 4.4: DPPH assay of the decoction at various concentrations

Figure 4.5: Erythrocyte SOD activity of rats after nine months

of decoction treatment in group $1(6 \mathrm{~g} / \mathrm{kg}$ body weight/day) 
when compared with the corresponding activity of DEN-control rats (group 2)

Figure 4.6: Plasma GPX activity of rats after nine months of decoction

treatment $(6 \mathrm{~g} / \mathrm{kg}$ body weight/day) when compared with the corresponding activity of DEN-control rats (group 2). 


\section{LIST OF PLATES}

Plate 1: Nigella sativa Linn.sp $\quad 68$

Plate 2: Hemidesmus indicus (L) R.Br. 69

Plate 3:Smilax glabra Rox b. $\quad 70$

Plate 4: Immunohistochemical staining of DEN-induced 139 glutathione S-transferase placental form positive (GST-P+) foci in Wistar rats

Plate 5: H \& E staining of normal liver, DEN-control liver and

$\mathrm{DEN}+$ decoction treated liver of rats after 9 months of treatemnt

Plate 6: $\mathrm{H}$ \& E staining of liver adenoma found in DEN -control group after 9 months of decoction treatment.

Plate 7: Silver impregnation staining for reticulin fibers in normal liver, 144 DEN-control liver and DEN + decoction treated liver of rats after 9 months.

Plate 8: Glutathione S-transferase P positive foci of rat livers treated with DEN only and DEN + decoction for 9 months

Plate 9: H \& E staining of heart sections from rats treated with decoction for 3 months and control rats treated with distilled water

Plate 10: $\mathrm{H} \& \mathrm{E}$ staining of lung sections from rats treated with decoction for 3 months and control rats treated with distilled water

Plate 11: $H$ \& E staining of liver sections from rats treated with decoction for 3 months and control rats treated with distilled water 
Plate 12: $\mathrm{H} \& \mathrm{E}$ staining of stomach sections from rats treated with decoction for 3 months and control rats treated with distilled water

Plate 13: $\mathrm{H} \& \mathrm{E}$ staining of duodenum sections from rats treated with 152 decoction for 3 months and control rats treated with distilled water

Plate 14: H \& E staining of kidney sections from rats treated with 153 decoction for 3 months and control rats treated with distilled water 


\section{ACKNOWLEDEMENTS}

My supervisors, Prof. (Mrs) S. M.D.N. Wickramasinghe, and Prof. (Mrs). M.I. Thabrew are deeply acknowledged for suggesting the topic and for their guidance and advice regarding laboratory investigations. Prof. (Mrs) S..M.D..N. Wickramasinghe is also greatly acknowledged for her encouragement, friendly supervision and creating stress less research environment. I also wish to express my foremost appreciation and gratitude to Prof. (Mrs). M.I. Thabrew, without whom this project might not have seen the end. Specially, this thesis would not have been made this beautifully without her. Thank you madam for all the hours you spent on this document.

My grateful thanks are due to Prof. N. Ratnatunge, Head of the Department, Department of Pathology, Faculty of Medicine, University of Peradeniya, Peradeniya, who stepped into the project at a time of great need, and without whose support and facilities at Department of Pathology, Faculty of Medicine, University of Peradeniya, the pathology aspects of the study could not have been completed.

My heartfelt gratitude to Dr. (Miss). Mayuri Thammitiyagodage, Veterinary Surgeon, Animal Centre, Medical Research Institute, (M.R.I), Colombo 08, who was also my coordinator at the M.R.I, for her assistance and guidance throughout the project and introducing me to my supervisors. Most of all I must thank her for all the fun we have had during the research period and for convincing me that work can be very enjoyable. 
My grateful thanks are due to Dr. (Mrs). Syamini Jayesekara, Head of the Department, Animal Centre, M. R.I, Colombo 08, who was like my unofficial supervisor at the M.R.I, trained me in handling and caring for laboratory animals, encouraged me and guided me in any difficult situation irrespective of the fact she is not directly involved in the project.

My gratitude also due to Dr. A. Weerasinghe, Department of Immunology, M.R.I, for the valuable guidance and providing monoclonal antibodies for the immunology experiments.

My sincere thanks to Dr. Nimal Jayathilake, Ayurveda Research Institute, Navinna, Maharagama, for providing the recipe for the formulation of this decoction and providing assistance whenever needed.

I also acknowledge with thanks the financial assistance given by the National Science Foundation, Colombo 07.

My heartiest gratitude goes to Prof. E. R. Janz, Prof. H. Peiris, Mrs. Sagarika Ekanayake, Ms. U. G. Chandrika and all the academic and non-academic staff members and all my fellow researchers at the Department of Biochemistry, Faculty of Medical Sciences, for the facilities provided and helping me in numerous ways to complete this project. 
My grateful thanks goes to Miss. Sujatha Ramadasa, Mr. K. Herath, and all the other technicians at the Department of Pathology, Faculty of Medicine, University of Peredeniya, Peradeniya and Mr. S. Sisira Kuamra, Mr. Jayasiri and all the animal supervisors and orderlies from the Animal Centre, M.R.I for technical assistance provided during the research period.

My gratitude also goes to Oushada Lanka (Pvt) Ltd., Katuwawala, for providing garlic powder.

Finally, I wish to thank my parents without whom this research would not have happened in the first place. For my mother, who encouraged me from the beginning and believed in me, without whose financial assistance, I would have given up the project long ago. For my father, who shouldered the massive task of collection of the raw materials for the preparation of the decoction daily for three years continuously, without as much as a comment. 


\section{Investigation of the effects of a traditional Sri Lankan}

\section{Medicine on hepatocarcinogenesis}

\section{S. S. Iddamaldeniya}

\section{ABSTRACT}

Hepatocellular carcinoma is among the eight leading causes of cancer deaths worldwide with a clear tendency to increase further. Therapeutic possibilities for this are very limited and prognosis is usually poor.

Several plant-based treatments are being recommended for cancer patients by traditional medical practitioners of Sri Lanka. However, none of these has been subjected to scientifically controlled investigation to validate their anti-cancer potential. One of these is a decoction comprised of Nigella sativa seeds, Hemidesmus indicus root and Smilax glabra rhizome.

In the present investigation protection against Diethylnitrosamine (DEN) -induced hepatocarcinogenesis was investigated in Wistar rats by the decoction using the medium term bioassay system of Ito, based on a two-step model of hepatocarcinogenesis. In previous studies, garlic has been shown to protect, rat liver against DEN-induced carcinogenesis. Therefore, it was used as a positive control in the present study. 
Objectives of the investigation were to determine,

1. whether a decoction of Nigella sativa, Hemidesmus indicus and Smilax glabra inhibits glutathione S-transferase (GST-P) expression in rat liver.

2. whether this decoction has any anti-tumour potential.

3. whether this decoction has any toxic side effects.

4. the mechanism/s of action/s by which the decoction mediates its anti-tumour activity.

Four studies (Studies 1,2,3, and 4) were conducted to achieve the above four objectives. In study 1 , the short-term effects of the decoction on GST-P+ expression in rat hepatocytes were investigated. Carcinogenic potential in study 1 was scored by comparing the number, area and staining intensity of GST-P positive foci and number of cells $/ \mathrm{cm}^{2}$ of the foci in the livers of rats treated with the decoction (test 1 and test 2) or garlic (positive control, control 2) for 10 weeks with those of the corresponding group (control 1) of rats given DEN and distilled water. Decoction dose 1 ( $4 \mathrm{~g} / \mathrm{kg}$ body weight/day) corresponding to the normal therapeutic dose, was administered to the test group of rats, while dose 2 , was given to the test 2 group of rats, provided a higher dose ( $6 \mathrm{~g} / \mathrm{kg}$ body weight/day).

Treatment with decoction dose 1 reduced significantly, (a) the number and area of GST-P positive foci, (b) number of cells $/ \mathrm{cm}^{2}$ of foci, (c) staining intensity of GST-P positive foci $(\mathrm{P}<0.01)$ compared with animals in control 1. Treatment with decoction dose 2 resulted in a further significant reduction in the above parameters $(\mathrm{P}<0.001)$. 
The reduction mediated by dose 2 was similar to that produced by garlic $(20 \mathrm{mg} / \mathrm{kg}$ body weight/day).

In study 2, the effects of long-term treatment (for 9 months) of the decoction on tumour development were investigated. Two groups were used- DEN only treated group (DEN-control) and DEN+ decoction treated group $(6 \mathrm{~g} / \mathrm{kg}$ body weight/day; test study). During the post mortem of rats after nine months, one hepatocellular adenoma (HA) was found in the DEN control group. Haematoxylin and Eosin staining of liver sections confirmed the HA and revealed altered hepatocyte nodules which may progress to HA. DEN and decoction treated group showed no HA. There were also very few nodules of altered hepatocytes which precedes HA. Reticulin stain was done to confirm the HA and to see whether it has progressed up to the hepatocellular carcinoma (HCC). DEN control group showed well-preserved reticulin framework of normal liver, which confirms that HA, has not yet progressed up to HCC. Test group showed expected normal liver reticular pattern.

Toxic effects of the decoction were investigated in study 3. Treatment with decoction dose 1 or dose 2 for three months had no adverse effects on the liver function (as assessed by its effects on serum levels of alanine and aspartate aminotrasnferase and alkaline phosphatase). Histopathological studies indicated that no significant histological changes had occurred in any of the major body organs (liver, kidney, lung, heart, stomach and duodenum) investigated. 
No significant changes in haematological parameters (red blood cell count, white blood cell count, haemoglobin concentration, packed cell volume, mean corpuscular haemoglobin, mean corpuscular volume and mean corpuscular haemoglobin concentration) were observed during treatment with this decoction. The investigations also demonstrated that the decoction did not possess anti- ovulatory, anti-implantation, and anti-spermatocytogenic properties.

The $\mathrm{LD}_{50}$ study showed that even at a dose of 40 times the highest dose $(6 \mathrm{~g} / \mathrm{kg}$ body weight/day), used in other experiments of the study, the decoction did not cause any mortality. Long-term (3 months) treatment with the decoction did not cause any changes in average feed consumption, average body weight gain, and body weight : liver weight ratios and the general behaviour of the animals.

In study 4, preliminary investigations were carried out to determine possible mechanism of action by which the decoction mediates its anti-cancer effects. Tests done for anti-oxidant activity showed that the dcoction significantly increases the activity of blood glutathione peroxidase and superoxide dismutase $(\mathrm{P}<0.05)$ with little radical scavenging activity. Studies on immunomodulatory activity indicated that the decoction could stimulate production of T lymphocytes and NK cells (CD8 and NK receptors) although the results were not statistically significant.

Overall results indicate that the decoction comprised of $N$. sativa seeds, $H$. indicus root and $S$. glabra rhizome can protect against chemically induced hepatocarcinogenesis with no significant toxic effects even when it was 
administered for a period of three months. Antioxidant activity and immunomodulation are two possible mechanisms by which the decoction mediates its anti-carcinogenic activity. 